\title{
DO LEIB À CHAIR - UMA AFIRMAÇÃO DO SENSÍVEL
}

\author{
Irene Pinto Pardelha
}

Universidade de Lisboa

\section{A Chair como traição comemorativa do Leib}

Todo o Sein und Zeit saiu de uma indicação de Husserl e não é, em suma, senão uma explicitação do "natüralichen Weltbegriff" ou do "Lebenswelt" que Husserl, no final da sua vida, atribuía como tema primeiro à fenomenologia, de modo que a contradição volta a reaparecer na fílosofia do próprio Husserl. ${ }^{1}$

Podemos em larga medida considerar que este comentário feito por Merleau-Ponty no Avant-propes da Phénoménologie de la Perception relativo ao supra-sumo testemunho da obra heideggeriana vale também para a obra merleau-pontyana. Não obstante, a história da filosofia é comparável a um imenso balancete cujo débito será sempre superior ao crédito. A célebre frase - de tão citada, já transformada em cliché - "Somos anões aos ombros de gigantes" é o estandarte de grande parte desta enorme dívida. De paternidade duvidosa - supostamente de Bernard de Chartres - este lema, hoje universal, esconde na sua unilateralidade as dimensões complexas dessa mesma dívida. Nós, anões, somos devedores porque nos apropriamos indevidamente do trabalho de gerações de gigantes que nos precederam ou, somo-lo, porque temos para com eles a obrigação da nossa dedicação e esforço, porque a única forma de agradecer é simplesmente continuar este trabalho sempre inacabado, esta busca infinita cujo objectivo é

\footnotetext{
Merleau-Ponty, "[...] tout Sein und Zeit est sorti d'une indication de Husserl et n'est en somme qu'une explicitation du 'natürlichen Weltbegriff' ou du 'Lebenswelt' que Husserl, à la fin de sa vie, donnait pour thème premier à la phénoménologie, de sorte que la contradiction reparaît dans la philosophie de Husserl lui-même", Phénomén logie de la Perception (1945), Paris, Gallimard, 2005, pp. $7-8$.
} 
ver mais longe do que o já visto ${ }^{2}$ Paradoxalmente, a nossa humildade e a nossa generosidade só serão verdadeiramente grandiosas quando, à consciência do peso desta dívida, se adicionar a tentativa de a levar cada vez mais longe, emancipando-a, pensando-a mais, e sobretudo, de outra maneira.

A comemoração do pensamento de um autor, que pelo seu esforço de pensar mais e de outra maneira lhe permitiu participar desta longa caminhada de gigantes que é a história da Metafísica, toma em Merleau-Ponty, não as proporções de uma dívida, mas de uma traição - nas palavras do próprio. É a título de grande elogio e agradecimento, que Merleau-Ponty se refere, em "Le philosophe et son ombre", ao pensador e ao homem Edmund Husserl, dizendo que "a respeito de um filósofo cujo empreendimento despertou tantos ecos, e aparentemente tão longe do ponto em que o próprio se deteve, toda a comemoração é também uma traição". ${ }^{3}$ Para compreender o alcance desta traição comemorativa de Merleau-Ponty ao pensamento husserliano, é necessário desbravar o sentido da noção de traição, para que possamos ultrapassar esta contradictio in terminus a que a expressão parece conduzir-nos. A partir da conotação negativa que lhe conhecemos, "traição" refere-se ao acto de faltar à confiança de alguém transmitindo um segredo que lhe havia sido confiado. Ora, em filosofia é tão absurdo falar em segredo como em revelação de uma verdade absoluta. Do latim clássico "tradere", um verbo composto pelo prefixo "trans" - "para além de" - e pelo verbo "dare" - "dar" - dá corpo a um dar em segunda mão, a um entregar para além do dado, numa palavra, a um transmitir ou a um ensinar. O "traditor" era assim o intermediário deste mesmo conteúdo, aquele que elucidava acerca de qualquer coisa que à partida se desconhecia. Só nesta acepção do termo parece lícito pensar a traição que Merleau-Ponty opera sobre o pensamento husserliano tendo em vista comemorá-lo.

Merleau-Ponty estava consciente que, inscrevendo o seu pensamento na tradição fenomenológica iniciada por Husserl, todos os elogios ao pensamento deste mestre se instituiriam como outra coisa para além daquilo que Husserl lhe legou. O autor da Phénoménologie de la perception, admite que depois de Husserl seria difícil instituir o seu pensamento fenomenológico como radicalmente outro - isto sim, seria uma traição em filosofia. Merleau-Ponty deseja pensar de forma diferente, ir mais longe através daquilo que Husserl não tinha pensado, porque não quis pensar ou porque não the foi possível fazê-lo. Por outro lado, se recusarmos a eman-

2 Esta questão é formulada da seguinte forma por Paul Ricœur: "Qu'est-ce qui est plus honorable, la solidité dans géant ou la vue perspicace d'un nain?", Paul Ricœur, La mémoire, l'histoire, l'oubli, Paris, Éditions du Seuil, p. 403.

3 Merleau-Ponty, “À l'égard d'un philosophe dont l'entreprise a éveillé tant d'échos, et apparemment si loin du point où il se tenait lui-même, toute commémoration est aussi une trahison", "Le philosophe et son ombre" in Signes (1960), Paris, Gallimard, 2003, p. 259. 
cipação da noção merleau-pontyana da Chair relativamente à teoria husserliana do Leib, a própria noção de verdade como procura infinita perde toda a sua legitimidade.

Por outro lado, esta comemoração do pensamento husserliano também pode ser compreendida, no mesmo artigo de Signes, a partir da noção heideggeriana de Ungedachte ou Noch-nicht-Gedacht, ${ }^{4}$ conceitos que remetem para esse horizonte de indagação que um grande pensamento sempre deixa em aberto. A ideia de um impensado ou de um ainda-não-pensado não surge em prejuízo do pensamento husserliano, muito pelo contrário, torna-o poroso, na medida em que o torna susceptível de ser olhado, penetrado de forma não-positiva (o que não significa "subjectiva"). Olhá-lo com olhos positivos numa acção de sobrevoo do pensamento ${ }^{5}$ seria abdicar dessa significação porosa, da espessura que é própria a qualquer obra filosófica. ${ }^{6}$ Apenas nesta acepção podemos compreender a influência que os manuscritos husserlianos tiveram no pensamento da Chair em Merleau-Ponty, como um imiscuir-se para além da superfície plana do texto, atravessando-o de uma ponta a outra. Jacques Derrida, negando a impossibilidade de olhar o texto sem nele tocar, ${ }^{7}$ diria que Merleau-Ponty só entrou no jogo porque nele arriscou tocar, já que (agora citando Husserl) "pela per-

4 Merleau-Ponty cita Heidegger, quando este se refere à riqueza do impensado de uma obra. Escreve Heidegger: "Je grösser das Denkwerk eines Denkers ist, das sich keineswegs mit dem Umfang und der Anzahl seiner Schriften deckt, um so reicher ist das in diesem Denkwerk Ungedachte, d.h. jenes, was erst und alleindurch dieses Denkwerk als das Noch-nicht-Gedachte heraufkommt" (No que se refere ao pensamento, quanto maior é a obra - que nunca coincide com a extensão nem com o número de escritos - mais rico é nesta obra o impensado, ou seja, o que através desta obra e só por ele, nos chega como o ainda-não-pensado) in Heidegger, Der Satz vom Grund, apud Merleau-Ponty, "Le philosophe et son ombre", in op. cit., p. 260.

5 "Pensamento de sobrevoo" é, em Merleau-Ponty, o pensamento que não se detém nas coisas, que as olha de cima, que as analisa numa visão meramente superficial, sem conseguir perceber que a Natureza é mais em profundidade do que em superficie (para retomar a expressão de Paul Cézanne).

6 Esta ideia de impensado pode ser melhor compreendida no capítulo "Interrogation et intuition", de Le visible et l'invisible, quando Merleau-Ponty sugere que, "s'il y a une idéalité, une pensée qui a un avenir en moi, qui même perce mon espace de conscience et a un avenir chez les autres, et enfin, devenue écrit, un avenir en tout lecteur possible, ce ne peut être que cette pensée qui me laisse sur ma faim et les laisse sur leur faim, qui indique un gauchissement général de mon paysage et qui l'ouvre à l'universel, justement parce qu'elle est plutôt un impensé", Merleau-Ponty, "Interrogation et intuition" in Le Visible et l'Invisible (1964), Paris, Gallimard, 1995, pp. 158-159.

7 Jacques Derrida, "Un texte n'est un texte s'il cache au premier regard, au premier venu, la loi de sa composition et la règle de son jeu [...] Réservant toujours une surprise à l'anatomie ou à la physiologie d'une critique qui croirait en 'maîtriser le jeu, en surveiller à la fois tous les fils, se leurrant aussi à vouloir regarder le texte sans y toucher, sans mettre la main à l' objet', sans se risquer à y ajouter, unique chance d'entrer dans le jeu en s'y prenant les doigts, quelque nouveau fil", "La Pharmacie de Platon" in La dissémination (1972), Paris, Éditions du Seuil, 1993, p. 79. 
cepção táctil sou sempre aquele que percebe no mundo, sei orientar-me nele e posso alcançar e conhecer o que quero". 8

\section{Do olhar natural ao olhar sobre a natureza}

A natureza enquanto simples natureza não contém valores, nem obras de arte, etc., que são contudo objectos de um conhecimento e de uma ciência possíveis. $^{9}$

É Natureza o primordial, ou seja, o não-construído, o não-instituído; daí a ideia de uma eternidade da Natureza (eterno retorno), de uma solidez. A Natureza é um objecto enigmático que não é propriamente objecto, ela não está propriamente diante de nós. Ela é o nosso solo, não o que está à frente, mas o que nos leva. ${ }^{10}$

A primeira citação é de Husserl, a segunda de Merleau-Ponty. Não obstante, poderíamos atribuí-la a um mesmo autor, cujo pensamento procurasse ultrapassar uma concepção de natureza que pudesse ser abarcada nos limites conceptuais de uma teoria científica ou filosófica. Ambas criticam uma visão da natureza como objecto já dado, capaz de ser apreendido ad aeternitas por uma consciência totalizadora. No entanto, o papel desta mesma natureza anterior a qualquer definição científica, toma diferentes nuances no pensamento de um e de outro autor.

A fertilidade do pensamento husserliano foi condição de possibilidade não de um novo olhar, mas de um olhar diferente sobre esta natureza cujas leis sempre constituíram um énigma para o próprio pensamento. A suposta transparência do olhar científico-natural circunscreve a natureza dentro dos limites de uma definição fechada e acabada, onde a verdade (qualquer que esta seja) não se processa pela tarefa continuada da investigação, mas pela necessidade de afirmação de uma teoria sobre outra. Como se imbricado na

${ }^{8}$ Husserl, "Par la perception tactile, je suis toujours percevant dans le monde, je sais m'orienter en lui et je peux saisir et connaître ce que je veux", Ideen zu einer reinen Phänomenologie und phänomenologischen Philosophie - Zweites Buch: Phänomenologische Untersuchungen zur Konstitution (1952). Idées directrices pour une phénoménologie et une philosophie pures Livre second: Recherches phénoménologiques pour la constitution, trad. fr. Eliane Escoubas, Paris, PLF, 1982, p. 108 - Este texto, sempre que citado, será designado por Ideen II.

9 Husserl, "La nature en tant que simple nature ne contient pas de valeurs, ni d'cuvres d'arts, etc., qui sont cependant objets d'une connaissance et d'une science possibles", Ideen II, p. 25.

${ }^{10}$ Merleau-Ponty dedicou uma parte do programa das aulas leccionadas no Collège de France, no ano académico de 1956-1957, ao conceito de natureza em Husserl. Nessas notas, reunidas na obra La Nature, figura "est Nature le primordial, c'est-à-dire le non-construit, le non-institué; d'où l'idée d'une éternité de la Nature (éternel retour), d'une solidité. La Nature est un objet qui n'est pas tout à fait objet; elle n'est pas tout à fait devant nous. Elle est notre sol, non pas ce qui est devant, mais ce qui nous porte", Merleau-Ponty, La Nature - Notes. Cours du Collège de France (1968), Paris, Éditions du Seuil, 1994, p. 20. 
estrutura mesma da verdade o relativismo a banalizasse. O mundo apenas como horizonte de experiência possível, como mero objecto natural que carece de uma definição totalizante não apreendida nos fundamentos, mas nas consequências. $\mathrm{O}$ empirismo em todo o seu esplendor!

Perante este mundo construído e não constituído, a fenomenologia husserliana apoia-se no pressuposto de que é possível superar $o$ mundo das ciências da natureza - ou do espírito - como horizonte de experiência possível, ou seja ultrapassar os limites que elas impuseram a si próprias. $\mathrm{O}$ mundo é definido por Husserl, no primeiro capítulo de Ideen I, como "soma de objectos de uma experiência possível e de um conhecimento possível por experiência, a soma dos objectos que, sob o fundamento da experiência actual (aktualler), podem ser conhecidos no quadro de um pensamento teórico correcto". "11 Esta formulação "correcta" do mundo, envolvida no mais profundo empirismo, é descrita por Husserl como sendo operada por uma atitude doxo-teórica, na medida em que tem como correlato intencional este mundo, cuja experiência é ainda formulada no âmbito da atitude natural. ${ }^{12}$

Esta incapacidade de o olhar científico-natural perceber a natureza como tal foi uma certeza que esteve também patente em toda a obra merleau-pontyana e podemos encontrá-la mesmo no seu último trabalho quando denuncia o pensamento científico como artificialismo absoluto. Escreve Merleau-Ponty, "dizer que o mundo é por definição nominal o objecto X das nossas operações, é elevar ao absoluto a situação do conhecimento do cientista, como se tudo o que foi ou é só tivesse sido para entrar no laboratório. O pensamento operatório transforma-se numa espécie de artificialismo absoluto"13 e mais grave ainda "o homem torna-se verdadeiramente no manipulandum que ele pensa ser, entramos num regime de cultura em que não há mais verdadeiro nem falso tocando o homem e a história, num sono ou num pesadelo dos quais nada poderia acordá-lo. É preciso que o pensamento de ciência - pensamento de sobrevoo, pensamento do objecto em geral - se situe num 'há' prévio, num sítio, sobre o solo do mundo sensível e do mundo 'obrado' tais como são na nossa vida,

${ }^{11}$ Husserl, "Monde est la somme des objets d'une expérience possible et d'une connaissance possible par expérience, la somme des objets qui, sur le fondement de l'expérience actuelle (aktueller), peuvent être connus dans le cadre d'une pensée théorique correcte", Ideen zu einer reinen Phänomenologie und phänomenologischen Philosophie (1928), Idées directrices pour une phénoménologie. Introduction générale à la Phénoménologie Pure (1950), trad. fr. Paul Ricœur, Paris, Gallimard, 1985, p. 15 - Sempre que citado, este livro será designado por Ideen I.

${ }^{12}$ Esta atitude própria das ciências da natureza é também denunciada nos primeiros capitulos da primeira secção de Ideen II, nomeadamente nos $\S \S 1,2$ e 3 .

${ }^{13}$ Merleau-Ponty, "Dire que le monde est par définition nominale l'objet $\mathrm{X}$ de nos opérations, c'est porter à l'absolu la situation de connaissance du savant, comme si tout ce qui fut ou est n'avait jamais été que pour entrer au laboratoire. La pensée "opératoire" devient une sorte d'artificialisme absolu", L'ail et l'esprit (1964), Paris, Gallimard, 2001, pp. 11 - 12. 
para o nosso corpo, não este corpo possível que é viável defender como uma máquina de informação, mas este corpo actual que chamo meu, a sentinela que se mantém silenciosamente sob as minhas palavras e sob os meus actos". 14

Constatamos então que a acusação do conhecimento científico operada por Husserl como pertencendo ainda ao domínio da doxa, transforma-se no primeiro passo em direcção a um tipo de conhecimento que visa ultrapassar a evidência não apodíctica da existência do mundo. ${ }^{15}$ A superação desta não apodicticidade requer uma conversão de atitude que questione as bases da atitude natural da qual parte, na medida em que ela acredita no mundo, mas ignora as razões da sua crença. Por isso tanto defende que é necessário que o próprio mundo se transforme em tema, onde a tematização do mundo surge como o resultado - sempre a reavaliar - de uma conversão do olhar operada pela passagem da atitude natural para a atitude transcendental, ou seja, o requisito para a fundamentação da ciência fenomenológica, uma vez que "se quisermos fundar as ciências de maneira radical, a evidência que nos dá a experiência do mundo necessita de qualquer modo de uma crítica prévia da sua autoridade e do seu alcance". ${ }^{16}$

Esta crítica prévia só é possível tendo como base a redução fenomenológica, que como nos diz Merleau-Ponty, não é apenas o começo da investigação, mas o todo, uma vez que "a investigação é [...] começo

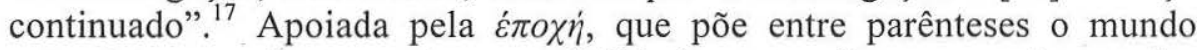
natural transcendente e cria a possibilidade para a dita conversão, a redução fenomenológica não tem como função negar o mundo do qual parte,

${ }^{14}$ Merleau-Ponty, op. cit., "[...] l'homme devient vraiment le manipulandum qu'il pense être, on entre dans un régime de culture où il n'y a plus ni vrai ni faux touchant l'homme et l'histoire, dans un sommeil ou un cauchemar dont rien ne saurait le réveiller. Il faut que la pensée de science - pensée de survol, pensée de l'objet en général - se replace dans un 'il y a' préalable, dans le site, sur le sol du monde sensible et du monde ouvré tels qu'ils sont dans notre vie, pour notre corps, non pas ce corps possible dont il est loisible de soutenir qu'il est une machine à information, mais ce corps actuel que j'appelle mien, la sentinelle qui se tient silencieusement sous mes paroles et sous mes actes", pp. 12 - 13. É necessário ter em conta que, em L'ail et l'esprit, a noção de corpo já não se encontra circunscrita à noção de Chair. Esta última já adquiriu uma autonomia própria, que não se encontra abrangida dentro da teoria da corporalidade pensada como Leib, na fenomenologia husserliana. Nesta obra, o domínio da Chair já abarca todo o âmbito do Sensível.

${ }^{15}$ Esta ideia da não apodicticidade da evidência do mundo é esboçada por Husserl tanto nas Méditations Cartésiennes como nas Ideen I.

${ }^{16}$ Husserl, "Si nous voulons fonder les sciences de façon radicale, l'évidence que nous donne l'expérience du monde nécessite de toute façon une critique préalable de son autorité et de sa portée", Méditations Cartésiennes (1947), trad. Gabrielle Peiffer e Emmanuel Lévinas, Paris, Vrin, 1996, p. 41.

${ }^{17}$ Merleau-Ponty diz-nos acerca dos problemas da redução que: "ils ne sont pas pour lui [Husserl] un préalable ou un préface: ils sont le commencement de la recherche, ils en sont en un sens le tout, puisque la recherche est, il l'a dit, commencement continué", Merleau-Ponty, "Le philosophe et son ombre" in op. cit., p. 262. 
mas reconduzi-lo à origem do seu sentido. $\mathrm{O}$ mesmo é dizer que a redução é condição de possibilidade da constituição do mundo como objecto intencional, ou seja, condição de possibilidade de toda a teoria da constituição. Pôr o mundo natural transcendente entre parênteses significa assim que o conteúdo do vivido da consciência de "mundo natural" não desaparece, mas é fundamentado teoricamente como a minha tomada de consciência sobre o mundo. O mesmo mundo no qual acredito na atitude natural é objecto de reflexão na atitude teórico-fenomenológica, já que a crença natural permanece na estrutura do próprio vivido "mundo". Se o mundo constituído como objecto intencional da atitude transcendental é o mesmo mundo, objecto transcendente da atitude natural, qual o motivo desta recondução?... Porque, como nos diz Merleau-Ponty, se esta ideia de natureza não é a única possível apenas nos resta justificá-la fundando ao mesmo tempo a sua legitimidade e ultrapassá-la. Já que “atrás deste mundo, há um mundo mais originário, anterior a toda a actividade, 'mundo antes de toda a tese"," ${ }^{18}$

$\mathrm{Na}$ medida em que pretende alcançar o carácter prévio subjacente ao fenómeno-mundo, a redução fenomenológica transforma-se no pilar fundamental da Fenomenologia como filosofia transcendental. Desta forma, no que diz respeito ao mundo como objecto intencional da minha consciência, só uma reflexão eidética dele se pode acercar. Não obstante, se Merleau-Ponty na Phénoménologie de la perception, elogia esta pretensão da fenomenologia em se instituir como Wesenschau, porque só uma forma de pensamento deste tipo "volta a colocar as essências na existência e não pensa que possamos compreender o homem e o mundo de outra maneira senão a partir da sua "facticidade", ${ }^{19}$ o mesmo não se passa em Le Visible et l'invisible. O progressivo afastamento da concepção fenomenológica husserliana obriga-o a pôr em causa a Fenomenologia como visão das essências, uma vez que, para ele, se torna cada vez mais evidente que a verdadeira questão filosófica não está em interrogar as essências e o mundo.

Mesmo se Merleau-Ponty acredita que uma "fé perceptiva" une o homem natural e o filósofo, uma fé expressa num olhar sobre o mundo que remete para esse fundo indizível de "'opiniões' mudas implicadas na nossa vida", também sabe que no momento mesmo em que procuramos explicar o que é nós, ver, mundo, já tematizamos, porque nós já não vemos o

${ }^{18}$ Em La Nature, Merleau-Ponty diz-nos acerca da redução fenomenológica que: "Derrière ce monde, il y a un monde plus originaire, antérieur à toute activité, 'monde avant toute thèse': c'est le monde perçu", Merleau-Ponty, La nature, p. 105.

${ }^{19}$ No início do Prefácio de Phénoménologie de la Perception, Merleau-Ponty define a fenomenologia como sendo também "une philosophie que replace les essences dans l'existence et ne pense pas qu'on puisse comprendre l'homme et le monde autrement qu'à partir de leur 'facticité' ", Merleau-Ponty, Phénoménologie de la Perception, p. 7. 
mundo. ${ }^{20} \mathrm{O}$ problema pode ser formulado da seguinte maneira: qualquer questão que queira ter como resposta o momento mesmo em que o Ser aparece, deve esquecer-se a si própria como questão, o que só seria possível se a interrogação partisse da ausência de sentido, recuasse ao nada. No entanto, o homem que se interroga é já ele alguma coisa, é já ele sentido e por isso, para o autor, "a dúvida é um positivismo clandestino, que é necessário ultrapassar em direcção a qualquer coisa que ela nega e que ainda afirma. Mas reciprocamente, se quiséssemos ultrapassá-la em direcção a uma esfera de absoluta certeza que seria aquela das significações ou das essências, este positivismo absoluto significaria que aquele que questiona afastou de tal forma de si o Ser e o mundo que deixou de existir. Como o negativismo da dúvida, o positivismo das essências diz secretamente o contrário do que diz abertamente". ${ }^{21}$

É nestes mesmos termos que Merleau-Ponty é levado a constatar, nos Cours du Collège de France de 1956-1957, que a fenomenologia husserliana sofre de um estrabismo congénito, já que dedica todos os seus esforços para ultrapassar a atitude natural e depois faz tudo para voltar a reabilitá-la. Husserl abriu a porta à afirmação do sensível, mas a fidelidade que sempre manteve para com as suas fontes impediram-no de entrar. A fundamentação da fenomenologia como método de conhecimento muito ficou a dever às categorias da modernidade que emanciparam o homem como mestre do seu destino, enquanto senhor das suas faculdades, mas não o libertaram do pesado e antigo jugo da inteligibilidade, apesar da modernidade sempre ter desejado demonstrar o contrário. Este apego às antigas categorias não é negado por Husserl e as referências modernas, tanto cartesianas como kantianas, dificilmente escondem o advento da razão nas Ideen II. Mesmo que, na sua primeira secção, Husserl afirme que a sensibilidade constitua a primeira camada na constituição do mundo, ${ }^{22}$ esta camada não nos aparece na terceira secção como possuindo uma estrutura

${ }^{20}$ Merleau-Ponty, "Nous voyons les choses mêmes, le monde est cela que nous voyons: des formules de ce genre expriment une foi qui est commune à l'homme naturel et au philosophe dès qu' il ouvre les yeux, elles renvoient à une assise profonde d' opinions' muettes impliquées dans notre vie. Mais cette foi a ceci d'étrange que, si l'on se demande ce que c'est nous, ce que c'est voir et ce que c'est chose ou monde, on entre dans un labyrinthe de difficultés et de contradictions", "Réflexion et Interrogation" in Le Visible et l'invisible, p. 17.

${ }^{21}$ Merleau-Ponty, "Nous disions que le doute est un positivisme clandestin, et qu'il faut le dépasser vers le quelque chose qu'il nie et qu'il affirme encore. Mais réciproquement, si l'on voulait le dépasser vers une sphère d'absolue certitude qui fût celle des significations ou des essences, ce positivisme absolu voudrait dire que celui qui questionne a tellement éloigné de soi l'Être et le monde qu'il n'en est plus. Comme le negativisme du doute, le positivisme des essences dit secrètement le contraire de ce qu'il dit ouvertement", "Interrogation et intuition" in op. cit., p. 160.

${ }^{22}$ Husserl, "Le monde réal se constitue originairement par étages de telle sorte que la multiplicité des 'sensualia' (les schèmes complets) s'édifie comme couche inférieure dans l'unité de la forme spatiale", Ideen II, p. 103. 
naturalmente sensível, mas como obedecendo a leis de concordância e discordância, enfim, uma camada ela também racional. Husserl defende aí que a diferença entre razão e sensibilidade é produto de uma "subjectividade dual", onde o "ego especificamente espiritual, este sujeito de actos do espírito, esta pessoa está dependente de um fundamento obscuro de traços de carácter, de disposições originárias e latentes que, pelo seu lado, estão dependentes da natureza"; e continua: "voltamos aqui à antiga diferença, que se nos impôs desde os primórdios, entre razão e sensibilidade. Esta última tem, ela também, as suas regras, quero dizer no sentido próprio das regras do entendimento, regras da concordância e da discordância, e isso constitui uma determinada camada racional, a da razão latente". ${ }^{23}$

Esta crítica é também apontada por Eliane Escoubas, que considera que "a teoria husserliana da Erscheinung se inscreve num equívoco relativamente aos princípios que a fundam", 24 já que por um lado supõe um logos organizador de um mundo geométrico centralizado por um Ich-Punkt, mas por outro lado, este mesmo logos é suportado pelos Sinnendingen, como Untergrund, fundamento da Erscheinung. Em Merleau-Ponty, este equívoco é expresso da seguinte forma: "o irreflectido", ou seja, a "razão latente" em Husserl "não é nem mantido tal e qual, nem suprimido, ele permanece um trampolim para a consciência. Ele joga o papel de um fundador e de um fundado; e reflectir é, assim, desvelar o irreflectido", ${ }^{25}$ ou seja, reflectir é acordar a razão em latência na sensibilidade.

Regressar às coisas mesmas não pode, para Merleau-Ponty, constituir um retorno às essências, um regresso ao momento onde o mundo se torna mundo como correlato intencional para uma consciência, mas um regresso - sempre impraticável - àquilo que ele apelida de l'Être sauvage. Para Husserl, "toda a percepção pura e simples de uma coisa" é "a consciência doadora originária da existência de uma coisa no presente" ${ }^{, 26}$ e esta mesma percepção só é possível enquanto movimento intencional onde "todos os raios partem, em testemunho do vivido, de um só e único ponto de partida,

${ }^{23}$ Husserl,"Cet ego spécifiquement spirituel, ce sujet des actes de l'esprit, cette personne est dépendante d'un soubassement obscur de traits de caractère, de dispositions originaires et latentes qui, pour leur part son dépendantes de la nature. Nous revenons ici à l'ancienne différence, qui s'est imposée dès les commencements, entre raison et sensibilité. Cette dernière a, elle aussi, ses règles, je veux dire au sens même des règles de l'entendement, des règles de la concordance et de la discordance, et c'est là une certaine couche rationnelle, celle de la raison latente", op. cit., p. 372.

${ }^{24}$ Eliane Escoubas, "La théorie husserlienne de l'Erscheinung s'inscrit dans une équivoque quant aux principes qui la fondent", "Préface" in Ideen II, p. 12.

${ }^{25}$ Merleau-Ponty, "L'irréfléchi, chez lui [Husserl], n'est ni maintenu tel quel, ni supprimé, il reste un poids et un tremplim pour la conscience. Il joue le rôle d'un fondant et d'un fondé; et réfléchir, alors, c'est dévoiler l'irréfléchi", La nature, p. 103.

${ }^{26}$ Husserl, op. cit., "[...] toute perception pure et simple de chose (je veux dire: Une conscience donatrice originaire de l'existence d'une chose au présent)", p. 43. 
o ego idêntico". ${ }^{27}$ Dificilmente o mesmo Merleau-Ponty, que nega a capacidade da interrogação filosófica apreender a essência das coisas, acreditaria na transparência da doação dessas mesmas coisas à consciência. As coisas dão-se à minha percepção na opacidade que lhe é própria, pois “o que há [...] não são coisas idênticas a elas mesmas, que depois, se ofereceriam ao vidente, anteriormente vazio, que depois, se abriria a elas, mas qualquer coisa da qual não poderíamos estar mais perto que palpando-as com o olhar, coisas que não poderíamos imaginar ver "completamente nuas', porque o próprio olhar as envolve e as veste com a sua carne". ${ }^{28}$

A minha percepção termina onde começam as coișas e estas acabam onde começa a percepção que tenho delas. Há uma penetração partilhada entre a percepção e as coisas, mas nunca descrita como usurpação manipuladora das próprias coisas. Não há imediatez ou coincidência no que se refere à apreensão do Ser das coisas. O pensamento merleau-pontyano lembra-nos que a fenomenologia deve dar-se conta dos seus próprios limites e compreender que esconder-se faz parte da essência das próprias coisas e que nenhuma forma de desvelamento pode torná-las inteligíveis, porque de nós ao Ser selvagem das coisas "não há nenhum caminho e que ele é por princípio inacessível. As coisas visíveis ao nosso redor repousam em si mesmas, e o seu ser natural está tão cheio que parece envolver o seu ser percebido, como se a percepção que delas tivéssemos se fizesse nelas. Mas, se exprimo esta experiência dizendo que as coisas estão no seu lugar e que nós nos fundamos com elas, torno-a impossível logo a seguir: pois, à medida que nos aproximamos da coisa, deixo de ser; à medida que sou, não há coisa, mas unicamente um duplo dela na minha 'câmara escura'. No momento em que a minha percepção se vai tornar pura, coisa, Ser, ela apaga-se; no momento em que se ilumina, já não sou a coisa". ${ }^{29}$

${ }^{27}$ Husserl, op. cit., Husserl diz-nos que no processo de apreensão do objecto “[...] tous ces rayons partent, au témoignage du vécu, d'un seul et unique point de départ, l'ego identique”, p. 159.

${ }^{28}$ Merleau-Ponty, "Ce qu'il y a donc, ce ne sont pas des choses identiques à elles-mêmes qui, par après, s'offriraient au voyant, et ce n'est pas un voyant, vide d'abord, qui, par après, s'ouvrirait à elles, mais quelque chose dont nous ne saurions être plus près qu'en le palpant du regard, des choses que nous ne saurions rêver de voir 'toutes nues', parce que le regard même les enveloppe, les habille de sa chair", "L'entrelacs - Le chiasme" in Le visible et l'invisible, p. 173.

${ }^{29}$ Todas as críticas tecidas ao idealismo ou a qualquer teoria da representação por Merleau-Ponty incidem sobre este ponto. O autor critica o facto da fenomenologia poder ser pensada como procura de coincidência ou de imediatez com o ser das coisas, porque "il n'y a de nous à lui, nul chemin, et, qu'il est par principe inacessible. Les choses visibles autour de nous reposent en elles-mêmes, et leur être naturel est si plein qu'il semble envelopper leur être perçu, comme si la perception que nous en avons se faisait en elles. Mais, si j'exprime cette expérience en disant que les choses sont en leur lieu et que nous nous fondons avec elles, je la rends impossible aussitôt: car, à mesure qu'on approche de la chose, je cesse d'être; à mesure que je suis, il n'y a pas de chose, mais seulement un double d'elle dans ma 'chambre noire'. Au moment où ma perception va devenir perception pure, chose, être, elle s'éteint; au moment où elle s'allume, je ne suis déjà plus la chose", Merleau-Ponty, "Interrogation et intuition" in op. cit., p. 163. 
Assim, tal como não há um Ich Punkt em Merleau-Ponty, também não há uma percepção pura que lhe esteja associada: percepção pura, para ele, é sinónimo de coisa, de Ser. Ao contrário de Husserl, o autor de Le visible et l'invisible, não consegue conceber a existência de um ego imutável e inicialmente vazio "dado numa ipseidade absoluta e na sua unidade que não possibilita nenhum esboço; ele deve ser captado, de maneira adequada, na conversão do olhar próprio à reflexão e que opera um regresso sobre si mesmo enquanto centro de função. Enquanto ego puro, não contém riquezas interiores latentes, é absolutamente simples, é dado ao grande dia, toda a sua riqueza reside no cogito e no modo da função, que aí pode ser captado de maneira adequada". ${ }^{30} \mathrm{O}$ cogito em Merleau-Ponty é tão só a espessura do meu corpo e, dessa mesma forma, não são as essências das coisas que são a extensão do meu corpo, mas as próprias coisas na sua capacidade de se tornarem visíveis para o meu olhar que as toca. Olhar e tacto não são em Merleau-Ponty sensualia que se destinam cada um deles à apreensão de uma propriedade distinta de uma mesma coisa, ${ }^{31}$ pois "é preciso habituarmo-nos a pensar que todo o visível é talhado no tangível, todo o ser táctil prometido de alguma forma à visibilidade, e que há sobreposição, enjambement, não somente entre o tocado e o tocante, mas também entre o tangível e o visível que está incrustado nele, como, inversamente, ele próprio não é um nada de visibilidade, não é sem existência visual". ${ }^{32}$.

Não obstante, a crítica merleau-pontyana à fenomenologia como Wesenschau, não põe em causa a necessidade de uma conversão do olhar em fenomenologia. O olhar natural, próprio do saber científico deve ser posto em causa, na medida em que, sobre o pretexto de revelar as leis com que o mundo se rege, manipula as coisas renunciando a habitá-las. O olhar natural deve metamorfosear-se em olhar sobre a natureza, mas a mesma fenomenologia que pretende captar a essência do mundo enquanto fenómeno para a consciência deve ter em conta que "a 'resposta' está acima dos 'factos', abaixo das 'essências', no Ser selvagem onde eram indivisos, e

${ }^{30}$ Acerca deste ego puro Husserl diz-nos que "il est [...] donné dans une ipséité absolue et dans son unité qui ne donne lieu à aucune esquisse; il doit être saisi, de façon adéquate, dans la conversion du regard propre à la réflexion et qui opère un retour sur lui en tant que centre de fonction. En tant qu'ego pur, il ne recèle pas de richesses latentes, il est absolument simple, il est donné au grand jour, toute sa richesse réside dans le cogito et dans le mode, qui peut y être saisi de façon adéquate, de la fonction", Husserl, op. cit., p. 157.

${ }^{31}$ Escreve Husserl, em Ideen II, que "pour les gens normaux, la structure chosique des choses ne s'édifie pas expressément à partir de 'visualia' et de 'tactalia'. Il y a une seule et même chose avec ses propriétés, dont les unes sont saisies par la vue de façon prépondérante ou exclusive (comme les couleurs et leurs différences), les autres par le toucher", Husserl, op. cit., p. 109.

32 Merleau-Ponty, "Il faut nous habituer à penser que tout visible est taillé dans le tangible, tout être tactile promis en quelque manière à la visibilité, et qu'il y a empiétement, enjambement, non seulement entre le touché et le touchant, mais aussi entre le tangible et le visible qui est incrusté en lui, comme, inversement, lui-même n'est pas un néant de visibilité, n'est pas sans existence visuelle", "L'entrelacs - Le chiasme" in op. cit., p. 177. 
em que, acima ou abaixo das clivagens da nossa cultura adquirida, continuam a sê-lo". 33

\section{Do Leib à Chair - uma afirmação do sensível}

Há incontestavelmente alguma coisa entre a Natureza transcendente, o em si do naturalismo, e a imanência do espírito, dos seus actos e dos seus noemas. É nesse entremeio que é preciso tentar avançar. ${ }^{34}$

A este propósito podemos já reter o caso particular em que o corpo (Körper) de que temos experiência no espaço e que é percebido por meio do corpo-próprio (Leib) é o corpo de carne (Leibkörper). ${ }^{35}$

Entre sensibilidade e razão, qual o lugar que Husserl dedica ao Leib no seu pensamento?... "A causalidade [...] depende da realidade, e os acontecimentos de consciência só têm uma realidade enquanto estados psíquicos, ou melhor, enquanto estados de um ego psíquico. Alma e ego psíquico 'têm' um corpo; existe uma coisa material de uma determinada natureza que não é uma coisa simplesmente material, mas que é Leib, logo: uma coisa material que, enquanto campo de localização de sensações e de afectos, enquanto complexo de órgãos dos sentidos, enquanto parte pregnante e contrapartida fenomenal de todas as percepções das coisas [...] constitui uma peça fundamental para o dado da alma e do ego". ${ }^{36}$

Desta forma, o âmbito do sensível continua na fenomenologia husserliana submetido às regras da rígida razão e se pudéssemos atribuir qualquer privilégio ao corpo husserliano seria em prol da relação imediata que mantém com o mundo tangível, já que "toda a coisa que vemos é uma coisa tangível e, enquanto tal reenvia a uma relação imediata com o Leib". ${ }^{37}$

. ${ }^{33}$ Merleau-Ponty, 'la 'réponse' est plus haut que les 'faits', plus bas que les 'essences' dans l'Être sauvage où ils étaient indivis, et où, par-derrière ou par-dessous les clivages de notre culture acquise, ils continuent de l'être", "Interrogation et intuition" in op. cit., p. 162.

${ }^{34}$ Merleau-Ponty, "Il y a incontestablement quelque chose entre la Nature transcendante, l'en soi du naturalisme, et l'immanence de l'esprit, de ses actes et de ses noèmes. C'est dans cet entre-deux qu'il faut essayer d'avancer", "Le philosophe et son ombre” in Signes, p. 270.

${ }^{35}$ Husserl, op. cit., "Nous pouvons à ce propos retenir tout de suite le cas particulier où le corps (Körper) dont on fait l'expérience dans l'espace et qui est perçu par l'entremise du corps propre (Leib) est le corps de chair (Leibkörper) lui-même", p. 206.

${ }^{36}$ Husserl, op. cit, "La causalité [...] relève de la réalité, et des événements de conscience n'ont une réalité qu'en tant qu'états psychiques, ou encore en tant qu'états d'un ego psychique. Ame et ego psychique 'ont' un corps; il existe une chose matérielle d'une certaine nature qui n'est pas une chose simplement matérielle, mais qui est chair, donc: une chose matérielle qui, en tant que champ de localisation et de sensations et d'affects, en tant que complexe d'organes des sens, en tant que partie prenante et contrepartie phénoménale de toutes les perceptions chosiques [...] constitue une pièce maîtresse pour la donnée de l'âme et de l'ego", p. 222.

${ }^{37}$ Husserl, op. cit., "Toute chose que nous voyons est une chose tangible et, en tant que telle, renvoie à un rapport immédiat au corps propre", p. 213 . 
Mesmo sendo o "ponto zero de toda a orientação", o Leib é apenas descrito enquanto pólo de motricidade voluntária que se dirige ao mundo como horizonte de tangibilidade, no qual ele próprio também é um tangível, susceptível de ser captado pelos sensualia de um outro Leib. Ou seja, o meu corpo transforma-se no motor perceptivo do Ich kann da consciência, pois "tenho consciência do meu corpo como de uma potência indivisa e sistemática de organizar determinados desdobramentos de aparência perceptiva". 38

Se é verdade que, na Phénoménologie de la perception, Merleau-Ponty partilha a mesma concepção de corpo pessoal, como Leib, é também verdade que o desdobramento do seu próprio pensamento fê-lo abandonar a ideia de que o Leib poderia albergar as dimensões ontológicas que desejava atribuir ao todo Sensível. Do Leib à Chair transforma-se assim num percurso descrito como dívida emancipada de um pensador em relação a outro, uma vez que Merleau-Ponty chegou a admitir que "a nossa corporalidade não pode ser posta no centro como o fiz na Phénoménologie de la perception, numa palavra, ela é apenas a dobradiça do mundo, a sua gravidade é tão só a do mundo. Ela não é senão um ligeiro desvio relativamente ao mundo". 39

Baseado na interpenetração não-osmótica daquele que vê no que é visto, sem existência de sujeito ou objecto, mas de uma carne total do Visível/ Sensível que se oferece ao movimento expressivo, Merleau-Ponty recusa qualquer tipo de distinção radical, pois "estas inversões, estas antinomias são diversas formas de dizer que a visão está presa ou faz-se do meio das coisas, aí onde um visível se põe a ver, torna-se visível por si e pela visão de todas as coisas, aí onde persiste, como a água-mãe no cristal, a indivisão do sentinte e do sentido". "Esta inseparabilidade não pode ser descrita em termos de transparência pura que desvelasse as coisas tal como elas me aparecem na percepção - lembremo-nos também que se a percepção fosse pura, transparente, ela deixaria de ser percepção e metamorfo-

${ }^{38}$ Merleau-Ponty É nestes termos que Merleau-Ponty se refere ao corpo como órgão do $E u$ posso da consciência: "J'ai conscience de mon corps comme d'une puissance indivise et systématique d'organiser certains déroulements d'apparence perceptive”, La nature, p. 107.

39 Renaud Barbaras escreve no capítulo "Le dédoublement de l'originaire - la Chair chez Merleau-Ponty et Husserl”, de Le tournant de l'expérience: “C'est d'ailleurs ce que note Merleau-Ponty dans un inédit: "Notre corporéité n'est pas à mettre au centre comme je l'ai fait dans Phénoménologie de la Perception: en un sens, elle n'est que la charnière du monde, sa pesanteur n'est que celle du monde. Elle n'est que puissance d'un léger écart par rapport au monde", Barbaras, "Le dédoublement de l'originaire - la Chair chez Merleau-Ponty et Husserl" in Le tournant et l'expérience. Recherches sur la philosophie de Merleau-Ponty, Paris, Vrin, 1998, p. 81.

${ }^{40}$ Merleau-Ponty, "Ces renversements, ces antinomies sont diverses manières de dire que la vision est prise ou se fait du milieu des choses, là où un visible se met à voir, devient visible pour soi et par la vision de toutes choses, là où persiste, comme l'eau mère dans le cristal, l'indivision du sentant et du senti", L'ail et l'esprit, pp. 19-20. 
sear-se-ia naquilo que percebe. A minha percepção não constitui um analogon das coisas que percebe, mas restitui-as com a mesma opacidade com que elas se lhe revelam. Assim, Merleau-Ponty defende que é necessário "que entre a exploração e o que ela me ensinará, que entre os meus movimentos e o que eu toco, exista alguma relação de princípio, algum parentesco, segundo o qual eles não sejam apenas, como os pseudópodes da ameba, vagas e efémeras deformações do espaço corporal, mas a iniciação e a abertura a um mundo táctil" ${ }^{41}$ E uma relação de parentesco implica simbiose, mas não osmose. Intimidade, mas não homogeneidade.

A própria percepção habita as coisas e dela se torna expressão, uma expressão originária que se dá a cada momento como abertura de novas possibilidades de instituir o mundo e não como seu esboço constitutivo. ${ }^{42}$ A consciência não joga o papel primordial na constituição do objecto porque perceber é ver e ver é habitar, porque "ver é entrar num universo de seres que se mostram, e [que] não se mostrariam se não pudessem estar escondidos uns atrás dos outros ou atrás de mim. Noutras palavras, ver um objecto é vir a habitá-lo e (dessa posição) captar todas as coisas segundo a face que elas voltam para ele. Mas na medida em que eu as vejo também a elas, elas são residências abertas ao meu olhar, e, situado virtualmente nelas, já percebo através de todos os ângulos o objecto central da minha visão actual". 43

${ }^{41}$ Merleau-Ponty, “Il faut qu'entre l'exploration et ce qu'elle m'enseignera, entre mes mouvements et ce que je touche, existe quelque rapport de principe, quelque parenté, selon laquelle ils ne sont pas seulement, comme les pseudopodes de l'amibe, des vagues et éphémères déformations de l'espace corporel, mais l'invitation et l'ouverture à un monde tactile", "L'entrelacs - le chiasme" in op. cit., p. 176.

${ }^{42}$ Merleau-Ponty dedica todo o semestre de Inverno de 1954-1955 do Collège de France à distinção das noções de "instituição" e de "constituição". A noção de "constituição" associada à filosofia kantiana e depois à filosofia husserliana dá-nos o mundo como constituído por acção de uma consciência constituinte: o constituído-mundo assimila-se à acção do constituinte-consciência. No caso da "instituição" não há coincidência entre instituinte e instituído e, por isso, Merleau-Ponty defende que o tempo é o modelo da instituição. O modelo da "instituição" torna-se na condição de possibilidade de novas séries de acontecimentos já instituídos. Contendo em si a passividade do instituído, de onde germina a potencialidade de ser do instituinte, o modelo da instituição transforma-se no horizonte sempre actual da fenomenalização daquilo que foi e será porque continua a sê-lo, na sua forma activa, instituinte. Não é do interesse deste artigo desenvolver em detalhe a problemática passividade-actividade, tema que será alvo de um outro estudo. Desta forma, remeto para "L'Institution dans l'histoire personelle et publique" in L'institution. La passivité - Notes de Cours du Collège de France (1954-1955), Paris, Éditions Belin, 2003, pp. 33 - 154.

${ }^{43}$ Merleau-Ponty, "Voir, c'est entrer dans un univers d'êtres qui se montrent, et ils ne se montreraient pas s'ils ne pouvaient être cachés les uns derrière les autres ou derrière moi. En d'autres termes: regarder un objet, c'est venir l'habiter et de là saisir toutes choses selon la face qu'elles tournent vers lui. Mais, dans la mesure où je les vois elles aussi, elles restent des demeures ouvertes à mon regard, et, situé virtuellement en elles, j'aperçois déjà sous différents angles l'objet central de ma vision actuelle", Phénoménologie de la Perception, p. 96. 
Assim, o meu corpo não se dilui nas coisas enquanto as habita, nem elas se dissolvem na prospecção óptica que o meu corpo opera nelas, porque "vemos as coisas, no seu lugar, onde estão, segundo o seu ser que é muito mais do que ser-percebido e, ao mesmo tempo, estamos afastados delas por toda a espessura do olhar e do corpo: é que esta distância não é o contrário desta proximidade, ela está de profundo acordo com ela, ela é sinónimo dela. A espessura da carne entre o vidente e a coisa é constitutiva da visibilidade que tem dela como da corporalidade que tem dele; não é um obstáculo entre ele e ela, é o seu meio de comunicação". ${ }^{44}$ A operação de significação surge neste comércio que é diálogo da carne consigo mesma. A carnalidade como "Ürpräsentierbarkeit" é o princípio elementar que tudo rege desde o princípio dos tempos, onde não se pode afirmar com certeza onde acaba a natureza e onde começa o homem ou a expressão. Por esta mesma razão, Merleau-Ponty afirma, no prefácio de Signes, que a história é a expressão da carne.

Podemos agora compreender o salto operado entre o Leib e a Chair. Se para Husserl a expressividade do Leib se resume à expressão do espírito que habita um corpo, ${ }^{45}$ para Merleau-Ponty é impossível compreender a noção de Leib como corpo sem que seja operada uma revisão do próprio conceito de cogito, já que "o organismo não é um constructum. Há um interior que não corresponde à imagem do $E u$ penso, e que nós não podemos compreender senão por representações bastardas. Toda a representação relativamente à produção natural é falsária por princípio". ${ }^{46}$ Assim, é necessário compreender este corpo que é o meu como Chair, como "ser de duas folhas": coisa entre as coisas e sentinte que as vê e as toca. Esta dupla pertença à ordem do "objecto" e do "sujeito", faz cair a dicotomia clássica entre sujeito e objecto, na medida em que os relaciona de forma quiasmática. O dito "sujeito" está entre os objectos, mas tocando-os e vendo-os, eles perdem a sua qualidade de objectos, porque fazem parte do tecido envolvente do Visível de que o meu corpo também como objecto faz parte, como se uma ténue teia existisse entre o meu dentro e o seu fora, entre o seu dentro e o meu fora, ou seja como uma relação a quatro tempos pressu-

${ }^{44}$ Merleau-Ponty, "Nous voyons les choses elles-mêmes, en leur lieu, où elles sont, selon leur être qui est bien plus que leur être-perçu, et à la foi nous sommes éloignés d'elles de toute leur épaisseur du regard et du corps: c'est que cette distance n'est pas le contraire de cette proximité, elle est profondément accordée avec elle, elle en est synonyme. C'est que l'épaisseur de chair entre voyant et la chose est constitutive de sa visibilité à elle comme de sa corporéité à lui; ce n'est pas un obstacle entre lui et elle, c'est leur moyen de communication", "L'entrelacs - le chiasme" in op. cit., p. 178.

${ }^{45}$ Escreve Husserl que "Leib, n'est pas seulement en géneral une chose, mais expression d'un esprit et, en même temps, organe d'esprit", Husserl, op. cit., p. 144.

${ }^{46}$ Merleau-Ponty, 'L'organisme n'est pas un constructum. Il y a un intérieur qui n'est pas à l'image de notre Je pense, et que nous ne pouvons comprendre que par des représentations bâtardes. Toute représentation à l'égard de la production naturelle est faussée par principe", La Nature, pp. 117 - 118. 
posta pela noção merleau-pontyana de "quiasma" e não a dois como o prescreve a noção de intencionalidade husserliana.

Um outro ponto de discórdia entre a fenomenologia merleau-pontyana e a husserliana diz respeito ao movimento intencional da Chair e do Leib em direcção às coisas do mundo. Para Husserl, o Leib "é órgão do querer, é apenas o único objecto que pode ser posto em movimento de maneira espontânea e imediata pelo querer do ego puro que é o meu, e é apenas o único meio para produzir um movimento espontâneo mediato de outras coisas". ${ }^{47}$ Sendo o Leib incapaz de mover-se de forma imediata senão por intermédio do querer do ego puro, conseguimos compreender também porque é que a intencionalidade fenomenológica pensada nos moldes de Husserl, é recusada no seu fundamento pela fenomenologia merleau-pontyana: afirmar tal operação seria aprisionar o olhar nos parâmetros de uma consciência que se dirige para as coisas, percebe-as e volta a si mesma para meditar sobre elas; como se as coisas estivessem ali, diante dela à espera de serem significadas na transparência de uma intenção significante. A recusa em aceitar esta transparência de contacto entre a consciência e o mundo pode ser compreendida a partir da seguinte constatação: se a reflexão só pode ser eidética, ela contribui para a aporia tanto da questão da corporalidade como da do mundo: uma reflexão que parte do sensível não pode pretender ascender à plena inteligibilidade. ${ }^{48}$

Segundo Merleau-Ponty, o movimento de reflexão só pode ser pensado como gesto de abertura do corpo relativamente ao mundo de que ele faz parte como vidente, mas também como visível, pois “o meu movimento não é uma decisão de espírito, um fazer absoluto, que decretaria, do fundo do seu aposento subjectivo, qualquer mudança de lugar miraculosamente executado na extensão. Ele é o seguimento natural e a maturação de uma visão". ${ }^{49} \mathrm{Na}$ minha interrogação já se encontra o apelo silencioso de. um mundo que me interpela, na medida em que, existindo perante mim, me incita a desvendar o enigma de cuja chave será sempre o único portador. Desta forma, o mundo não pode ser pensado como o objecto $\mathrm{X}$, que está aí imóvel perante mim e que continuamente faço meu numa lógica de sucessão e concordância. A consciência não esclarece o mundo e este não é passivamente esclarecido pela consciência. Como não há percepção pura, não

${ }^{47}$ Husserl, op. cit., "Pris déjà en tant que corps propre [...] il est organe du vouloir, il est le seul et unique objet qui peut être mis en mouvement de manière spontanée et immédiate par le vouloir de l'ego pur qui est le mien, et le seul et unique moyen pour produire un mouvement spontané médiat d'autres choses", p. 215.

${ }^{48} \mathrm{Na}$ tentativa de demonstração deste enunciado incide toda a crítica à fenomenologia husserliana como Filosofia das essências abordada em Merleau-Ponty, "Réfléxion et Interrogation" in op. cit., pp. $17-74$.

${ }^{49}$ Merleau-Ponty, “Mon mouvement n'est pas une décision d'esprit, un faire absolu, qui décréterait, du fond de la retraite subjective, quelque changement de lieu miraculeusement exécuté dans l'étendue. Il est la suite naturelle et la maturation d'une vision", L'œil et l'esprit, p. 18. 
há consciência pura nem pureza na correlação que une os dados da sensibilidade ao fluxo dos vividos da consciência, pois "colocando em face do espírito, morada de toda a clareza, o mundo reduzido ao seu esquema inteligível, uma reflexão consequente dissipa toda a questão no que toca à sua relação, que é doravante de correlação pura: o espírito é o que pensa, o mundo o que é pensado, não poderíamos conceber nem sobreposição de um sobre o outro, nem confusão de um no outro, nem passagem de um ao outro, e nem mesmo contacto entre eles, - um sendo para o outro como o unido ao que une ou o naturado ao naturante, eles são demasiado perfeitamente coexistentes para que um possa alguma vez ser precedido pelo outro". 50

Desta forma, o quiasma, como movimento de reciprocidade relacional da Chair, torna possível a abolição das dicotomias que colocam corpo e visível de um lado e aquilo que vê do outro, porque as dicotomias só são evidentes à superfície, mas o meu corpo visível, tal como a minha visão são também abarcados pela profundidade e suportados pelo meu corpo que vê. Assim, “o mundo visto não está 'no' meu corpo e, em última instância, o meu corpo não está 'no' mundo visível: Chair aplicada a uma Chair, o mundo não o envolve nem é envolvido por ele" envolvência quiasmática da Chair. É nesta relação a quatro tempos do meu corpo consigo mesmo, do meu corpo com o mundo, do mundo com o meu corpo e do mundo consigo mesmo, que a percepção da Chair como elemento constitutivo universal deve constituir um enigma e um tema para o pensamento reflexivo, já que "a doação em Chair é a iniciação primeira a um mundo, ela é o acto pelo qual qualquer coisa nos é originariamente dada, a prova dum 'há' que não se confundindo com a presença objectal, não exclui uma dimensão de ausência ou de retraimento. Longe de ser sinónimo de intuição, a presença carnal é o fundo a partir do qual qualquer coisa como um objecto pode ser dotado de sentido". 52

${ }^{50}$ Merleau-Ponty, "Mettant en face de l'esprit, foyer de toute clarté, le monde réduit à son schéma intelligible, une réflexion conséquente fait évanouir toute question touchant leur rapport, qui est désormais de corrélation pure: l'esprit est ce qui pense, le monde ce qui est pensé, on ne saurait concevoir ni empiétement de l'un sur l'autre, ni confusion de l'un avec l'autre, ni passage de l'un à l'autre, et pas même de contact entre eux, - l'un étant à l'autre comme le lié au liant ou le naturé au naturant, ils sont trop parfaitement coexistensifs pour que l'un puisse jamais être précédé par l'autre", "Réflexion et Interrogation" in op. cit., p. 71.

${ }^{51}$ Merleau-Ponty, “Le monde vu n'est pas ‘dans' mon corps, et mon corps n'est pas 'dans' le visible à titre ultime: chair appliquée à une chair, le monde ne l'entoure ni n'est entouré par elle", "L'entrelacs - Le chiasme" in op. cit., p. 182.

52 Barbaras, "La donation en chair est l'initiation première à un monde, elle est l' 'acte' par lequel quelque chose nous est originairement donné, l'épreuve d'un 'il y $a$ ' qui, ne se confondant pas avec la présence objectal, n'exclut pas une dimension d'absence ou de retrait. Loin d'être synonyme d'intuition, la présence charnelle est le fond à partir duquel quelque chose comme un objet peut être doué de sens", "Le dédoublement originaire. La Chair chez Merleau-Ponty et Husserl" in op. cit., p. 85. 
Em suma, sabendo que a teoria da corporalidade em Merleau-Ponty fundou os seus alicerces na noção de Leib husserliana é necessário pensar que limitar a Chair aos limites circunscritos do Leib husserliano é fechar os olhos ao facto de que a primeira se inscreve como outra coisa, como um Noch-nicht-Gedachte. Partindo ambos da noção de percepção como nível básico da constituição do Sensível, Merleau-Ponty vem a dar à mesma noção os contornos ontológicos que a noção de Leib husserliana não possuía. Husserl viu na percepção como doação originária a condição de possibilidade do mundo se dar na sua verdadeira essência, não enquanto totalidade constituída, mas enquanto teoria das Abschatungen continuamente a constituir. O Schema é, para ele, já uma unidade de manifestação no seio da diversidade dos esboços, onde o diverso só pode ser entendido como "uma extensão corporal preenchida de forma sensível", 53 em que o movimento - partindo de um ponto zero centralizador da minha orientação tridimensional - é o responsável pela apreensão de tal ou tal aspecto do real, nunca apreendido como objecto-total, mas como sensualia. De raiz fortemente kantiana, a ideia de esquematismo sofre uma alteração na medida em que, apesar do mundo ser apenas aquilo que vale para a minha consciência, Husserl não nega a existência do mundo, apesar da sua evidência não lhe ser apresentada como apodíctica. No entanto, o movimento intencional parte de uma subjectividade transcendental vazia que se torna na principal responsável pela constituição do mundo como objecto intencional, uma vez que a própria sensibilidade é atravessada pelos actos da consciência. A sensibilidade como "razão latente", ao mesmo tempo que reforça a ideia de um Ich-Punkt centralizador, abre a porta para afirmação do sensivel como parte integrante da própria constituição do real.

Desta forma, se a redução fenomenológica, pensada nos moldes husserlianos, é considerada inicialmente por Merleau-Ponty a única via possível para a apreensão do objecto-mundo enquanto tal, o percurso próprio ao pensamento merleau-pontyano leva-o a negar a possibilidade desta doação originária do ser das coisas ao movimento de percepção. A relação entre o meu corpo e o mundo, sendo descrita em Merleau-Ponty, em termos de quiasma e entrelaçamento, dificilmente daria a primazia a uma das partes integrantes da teoria da constituição, começando assim por abolir as noções de sujeito e objecto num movimento de afirmação do sensível. Esta relação que descreve o movimento expressivo da carne nega a existência do mundo como mero tema para a consciência: o Ser selvagem das coisas foge aos limites da própria percepção. Tal como em Heraclito, o Ser do Visível tende à ocultação e, como o movimento perceptivo do meu corpo foge às

${ }^{53}$ Para Husserl "[...] pour la chose matérielle, le divers, qui fonction en tant qu'état, est du type schème (une étendue corporelle remplie de forme sensible). Le schème eșt lui-même déjà une unité de manifestation, plus exactement: une unité dans la multiplicité des esquisses", Husserl, op. cit., p. 185. 
leis da imediatez e da coincidência, a minha percepção nunca poderá ser pura. Afirmar a pureza da percepção levaria à afirmação da própria transparência do acto de doação, que em Merleau-Ponty, só pode ser pensado em termos de partilha e logo de opacidade. A expressividade da carne como elemento ontológico do real não pode negar à carne do mundo a sua forma prỏpria de se expressar.

Assim, a percepção em Merleau-Ponty não é doação originária da coisa, na medida em que "não a despe com o olhar", ela toca-a, "envolve-a e veste-a com a sua carne", mas 'cada percepção é 'variável' e somente provável; se quisermos, é tão-somente uma opinião; mas o que não o é, o que cada percepção, mesmo falsa, verifica, é a pertença de cada experiência ao mesmo mundo, o seu igual poder de o manifestar, a título de possibilidades do mesmo mundo", e continua: "se uma [percepção] toma tão bem o lugar da outra, - ao ponto de não lhe encontrarmos mais o rasto um momento após a ilusão, - é precisamente porque elas não são hipóteses sucessivas tocando um Ser desconhecido, mas perspectivas de um mesmo Ser familiar, do qual sabemos que não pode excluir uma sem incluir a outra, e que qualquer que seja a situação, ele mesmo, é incontestável". ${ }^{4}$

Não obstante, todas as críticas feitas por Merleau-Ponty à fenomenologia husserliana, estas não podem ser consideradas como destrutivas, mas como tentativas de compreensão dos movimentos da própria Chair, não da sua, mas da Chair enquanto carne fundante e fundada na própria história do Ser. Uma história não linear, mas feita de dobras, pregas do próprio pensar enquanto se curva perante as coisas e perante si próprio. Desta forma, o Leib husserliano ou a Chair merleau-pontyana nunca poderão ser pensados de forma sucessiva, um não foi causa da outra, mas um tornou-se horizonte do conhecimento possível da outra. Ambas integram o mesmo tecido de carne no qual são tecidas por todos aqueles que reflectem sobre as coisas habitando-as e não manipulando-as à maneira do pensamento científico natural - ele próprio obra manifesta da própria carne.

Assim, se em Husserl "não há Welt fora da Umwelt", ${ }^{55}$ em Merleau-Ponty, não há mundo fora da carne, elemento constituinte de todas as coisas, que as penetra, as habita, as comunica tanto "na sua linguagem indi-

\footnotetext{
${ }^{54}$ Merleau-Ponty, 'Chaque perception est muable et seulement probable; si l'on veut, ce n'est qu'une opinion; mais ce qui ne l'est pas, ce que chaque perception, même fausse, vérifie, c'est l'appartenance de chaque expérience au même monde, leur égal pouvoir de le manifester, à titre de possibilités du même monde. Si l'une prend si bien la place de l'autre, - au point qu'on ne trouve plus trace un moment après de l'illusion, - c'est précisément qu'elles ne sont pas des hypothèses successives touchant un Être inconnaissable, mais des perspectives sur le même Être familier dont nous savons qu'il ne peut exclure l'une sans inclure l'autre, et qu'en tout état de cause il est, lui, hors de conteste", "Réflexion et Interrogation" in op. cit., p. 64.

${ }^{55}$ Escoubas, "[...] il n'y a pas de Welt hors l'Umwelt", "Préface" in op. cit., p. 14.
} 
recta" como "nas suas vozes do silêncio". 56 Tal como para todos os enigmas, para este da Chair, qualquer palavra ficará sempre aquém do verdadeiro sentido daquilo a que se refere. Assim, se com todas estas palavras o mistério que envolve a noção de Chair ou de Leib não desvelou um pouco mais da sua carne, como visibilidade do invisível, espero que a metáfora possa cumprir um pouco mais essa função:

O mundo é como esta faixa de espuma sobre o mar vista de avião, que parece imóvel, e de repente, porque ela ficou uma linha mais espessa, compreendemos que, de perto, ela é corrente e vida, mas também que, vista de suficientemente alto, a amplitude do ser nunca superará a do nada, nem o barulho do mundo o seu silêncio. ${ }^{57}$

\section{Résumé}

Cet article a comme objectif premier de montrer comment une trahison peut aussi être la commémoration de la pensée d'un auteur. Ayant pour point de départ la lecture de Ideen II, la pensée de la Chair de Merleau-Ponty s'éloigne progressivement de sa source et s'institue comme dette-émancipée de la phénoménologie husserlienne. La Phénoménologie husserlienne en tant que Wesenschau donne le primat à la conscience comme pole noétique et la pensée merleau-pontyenne s'incline davantage à refuser la dichotomie noèse-noème, dans une émancipation progressive de la couche du Sensible, où la Chair acquiert des contours ontologiques. Comme conséquence, le mouvement intentionnel de mon corps en tant qu'organe du Ich kann de la conscience, devient, chez Merleau-Ponty, mouvement chiasmatique.

${ }^{56}$ Faço apelo ao texto "Le langage indirect et les voix du silence», que Merleau-Ponty dedica a Jean-Paul Sartre, mas que tem como interlocutor a obra Les voix du silence, de 1951, de André Malraux. Merleau-Ponty, "Le langage indirect et les voix du silence" in Signes (1960), Paris, Gallimard, 2003, pp. $63-135$.

${ }^{57}$ Merleau-Ponty, "[...] le monde est comme cette bande d'écume sur la mer vue d'avion, qui semble immobile, et soudain, parce qu'elle s'est élargie d'une ligne, on comprend que de près, elle est ruissellement et vie, mais aussi que vue d'assez haut, l'amplitude de l'être ne passera jamais celle du néant, ni le bruit du monde son silence», "Interrogation et dialectique" in Le Visible et l'Invisible (1964), Paris, Gallimard, 1995, p. 93. 